\title{
Esporte moderno e mediação pedagógica nas aulas de educação física
}

CDD. 20.ed. 796.017

796.5
Thiago PIMENTA* Tony HONORATO***
*Universidade Integradas do Brasil. *Universidade Estadual de Londrina.

\section{Resumo}

0 objetivo deste estudo foi identificar, mediar e problematizar os conceitos de esporte formados pelos alunos. A perspectiva da mediação pedagógica, em especial as contribuições de FontAnA (2000) e leitura sociológica de BOURDIEU (1983), foram fundamentos teóricos para pensarmos os conceitos de esporte produzidos em aula. A pesquisa, caracterizada como participante, foi realizada com alunos de sextas e sétimas séries de uma Escola Estadual localizada na cidade de São Paulo. Os dados foram sistematizados em relatórios referentes às aulas mediadas pelo professor/pesquisador. A partir da mediação pedagógica e da análise dos relatórios é possivel considerar que houve mudança de pensamento dos estudantes em relação ao fenômeno esportivo na direção da natureza sociocultural.

UnITERMos: Educação física; Pedagogia; Conteúdo; Esporte; Estudante.

\section{Introdução}

O esporte moderno é consideravelmente uma manifestação repleta de bens objetivos e simbólicos que exercem influência sobre as ações individuais e sociais. No século XX ele tornou-se uma prática mercantilizada e espetacularizada, haja vista a evolução da estrutura de pensamento do mágico mítico ao racional, o avanço do capitalismo valorizando as atividades atléticas como produtos e o aumento de sua presença cultural nos meios de comunicação. $\mathrm{O}$ fato é que existe um tratamento do esporte como bem específico a ser consumido.

Para LiPOVETSKY (2007), o esporte como bem de consumo desperta nos indivíduos o desejo de prática e de compra com prazer seduzido especialmente pela publicidade. Esta se estrutura nas imagens apoiadas nas práticas dos homens fascinados pela superação de si, pela busca do êxito, pela conquista de vitórias e pela aquisição de produtos esportivos. Assim, o esporte e a sociedade têm provocado nos indivíduos um vazio existencial, cuja compensação tem sido no consumismo exacerbado questionado muitas vezes por nós educadores.

Como elemento da sociedade, o esporte, lembra-nos Pierre BOURDIEU (1983), forma um campo com lógica específica constituída por um conjunto de agentes, instituições, disputas, representações, práticas, serviços e produtos de consumo disponíveis e socialmente aceitáveis em nosso tempo. O esporte configura um tipo de aprendizagem social, cultural, política e motora, que requisita análise de como as pessoas o conceituam.

É desafiador compreender as conceituações de esporte produzidas pelos indivíduos no interior das instituições relacionadas com o campo esportivo. Neste sentido a instituição escolar, onde há o componente curricular chamado Educação Física, é um lugar privilegiado para produzir e identificar conceitos presentes na formação do pensamento esportivo dos alunos.

Comumente, a carência de reflexão sobre o fenômeno esporte por parte dos alunos - associada às informações advindas dos meios de comunicação e às aulas onde o professor se limita ao ensino de regras e prática "per se" das modalidades esportivas - contribui de maneira significativa para ocultar a dimensão do consumo passivo requisitado pela lógica mercantil.

Nesta pesquisa tomamos então como objeto de estudo o conhecimento que os alunos têm sobre o esporte moderno, uma vez que fugir deste fenômeno não resolveria o problema posto na ordem social contemporânea. Assim, a questão norteadora da pesquisa foi: quais os conceitos de esporte são produzidos pelos alunos durante as aulas de Educação Física em 
uma instituição escolar? Com auxílio dos princípios da mediação pedagógica na sala de aula (FONTANA, 2000), o objetivo foi identificar, mediar e problematizar conceitos de esporte formados pelos alunos de sextas e sétimas séries do ensino fundamental de uma Escola Estadual localizada na cidade de São Paulo.
A concepção de Educação Física Escolar presente neste estudo é a que procura fundamentar-se numa perspectiva sociocultural de homem e de sociedade (Betti, 1999, 2006; Neira \& Nunes, 2006; ResenDE, 1994; Rocha, Winterstein \& Amaral, 2009; Silva \& Daolio, 2009).

\section{Método}

A pesquisa foi de natureza qualitativa a qual objetiva compreender pressupostos de uma realidade, os quais não podem ser quantificados e que a presença do pesquisador é essencial para identificar os conceitos fundamentais à vida das pessoas (TRIVIÑos, 1987). O tipo de pesquisa foi a participante, em razão de ter enfoque social, por meio do qual se busca plena participação das pessoas envolvidas no processo de geração de conhecimento, na análise de sua própria realidade e na promoção de uma ação formativa (BRANDÃO, 2001).

Os pressupostos metodológicos da mediação pedagógica, elaborados por FonTANA (2000) colaboraram para traçar não só o processo em estudo, mas trabalhar dentro dele nas aulas de Educação Física. Segundo FonTAna (2000) a mediação pedagógica, entendida a partir de Vigotsky e Bakhtin, considera os processos de conceituação dos indivíduos como uma prática social dialógica (mediada pela palavra) e pedagógica (mediada pelo outro).

A metodologia deste estudo assumiu de BAKHTIN (2002), autor da área da filosofia da linguagem, que pesquisar processos de conceituação é reconhecer a atividade mental mediatizada pelo discurso interior e exterior de quem aprende entrecruzando e confrontando valores sociais. Já da psicologia históricocultural de VYGOTSKY (1995, p.141) sistematizou-se que a conceituação de esporte produzida pelo aluno passa por uma internalização interligada ao seu desenvolvimento psíquico e cultural, do seguinte modo: a) os alunos e suas funções psíquicas se determinam primeiramente pela situação objetiva ( $\mathrm{em} s i=$ algo que está dado, neste estudo o conceito de esporte); b) o conceito de esporte recebe significação das pessoas (alunos e professor) que o rodeiam (para outros = emergem relações, debates, representações, cultura, coletividade); c) por último, o conceito de esporte para o outro é significado pelo próprio aluno na esfera interna (para si = o aluno internaliza as significaçōes constituindo o cultural esportivo de sua individualidade através das relaçôes com os outros). Há uma internalização que transforma conceitos de um plano interpessoal, em um plano intrapessoal, formando a consciência do aluno. Esta só emerge como tal, ou seja, como função, a partir de um princípio explicativo: relaçôes sociais. Assim, foi pertinente provocar diálogos antes da escrituração dos alunos sobre os conceitos de esporte, assim promovendo, conforme as considerações de Rocha, Winterstein e Amaral (2009), interação social entre os sujeitos.

A perspectiva da mediação pedagógica trouxe também para o desenvolvimento desta pesquisa procedimentos como:

a) o pesquisador/professor - é aquele que assume uma intervenção sobre a realidade para conhecê-la, transformando-a em suas condições de produção conceitual e prática;

b) escolha dos indivíduos - a opção foi por estudantes de sextas e sétimas séries por compreender que nestes níveis de escolaridade é possível desenvolver a habilidade do analisar, sistematizar e teorizar;

c) conceitos trabalhados - em coerência com a proposta da mediação pedagógica, os conceitos não foram estabelecidos "a priori”. Foi delimitada uma área do currículo - esporte - possibilitando que os estudantes apresentassem marcas e sentidos da realidade esportiva em que vivem.

$\mathrm{O}$ caminho assumido pelo pesquisador foi o de atuar como docente, configurando de forma concomitante a prática de pesquisa e a prática pedagógica por ele desenvolvida. Cabe destacar que esta senda apresenta possibilidades e limites metodológicos. Um limite é o lugar social de professor assumido pelo pesquisador, pois o professor/ pesquisador acaba estabelecendo diretrizes de seu trabalho pedagógico, para tanto, é relevante ao longo do trabalho criar uma sensibilidade para ir definindo e apurando seu papel no aprendizado dos alunos e no processo da pesquisa participante. Um outro limite é o da interpretação sobre as condições concretas de vida dos alunos extra-escola também presente na elaboração conceitual, dessa maneira esta pesquisa 
participante tomou como referência principalmente as condições concretas das atividades e dos conhecimentos produzidos pelos alunos no contexto das aulas de Educação Física. Este estudo limitou-se a estudantes de sextas e sétimas séries, portanto são pertinentes novas pesquisas com diferentes seriações.

Como possibilidade, destaca-se o ato do estudante poder expressar e lançar mão dos conhecimentos e experiências de seu universo social, para elaborar e incorporar os saberes da Educação Física Escolar a serem organizados pelo professor/pesquisador. Uma outra possibilidade é o professor/pesquisador fazer uso de uma proposta de ensino diferente da lógica da pedagogia tradicional herbartiana, a qual o docente é o centro do processo educativo na preparação, apresentação, associação, generalização e aplicação dos conhecimentos. Assim, na perspectiva da mediação pedagógica, ensinamento e produção dos dados de pesquisa passam por uma dimensão relacional e participativa entre educando e educador-pesquisador. Portanto, o pesquisador assume como foco de interesse o modo como se desenvolve o processo de apropriação/elaboração, pelos alunos, dos conceitos sistematizados na dinâmica da instituição escolar.

\section{Delimitando e sistematizando o estudo}

A pesquisa foi realizada no ano de $2006 \mathrm{em}$ uma Escola Estadual, localizada na periferia da zona norte da cidade de São Paulo. Este estabelecimento ofertava ensino fundamental e médio, e no ano de 2006 tinha aproximadamente 1200 alunos matriculados. A Escola possui um projeto pedagógico que adentra as necessidades da comunidade. Projetos didático-pedagógicos poderiam ser propostos pelos professores desde que atentassem ao caráter interdisciplinar. Considerando essa possibilidade e a condição de professor recém efetivo no quadro do magistério do Estado de São Paulo, a iniciativa de uma mediação pedagógica acoplada a uma pesquisa participante surgia como um caminho interessante para o professor/pesquisador.

Para tanto, a primeira ação do professor/pesquisador foi conhecer o plano anual de ensino, disponível na Escola, a ser desenvolvido na disciplina Educação Física para os estudantes de sextas e sétimas séries, turmas escolhidas também porque estavam sob a responsabilidade do professor/pesquisador. A segunda ação foi ter contato com os alunos em sala de aula. Já a terceira foi sugerir as seguintes diretrizes:

a) Conteúdo: esporte moderno;

b) Necessidade: reconhecimento do esporte enquanto fenômeno social institucionalizado que organiza vontades, padrões de gostos e pensamentos;

c) Objetivos: potencializar a formação de alunos críticos e participativos em relação à cultura esportiva; evidenciar, por meio das modalidades esportivas, que o esporte é um veículo de consumo carregado de bens objetivos e simbólicos;

d) Procedimentos: vivência das modalidades esportivas; conhecimento do conceito de esporte a partir dos alunos; problematização do conceito buscando conscientizar-se dos atos de pensamento que tal tarefa exigiu; sistematização do conceito e problematização da sistematização.

As diretrizes vão além de caminhos ordenados passo a passo, a sua proposição é mediar na dinâmica da interação como forma de viabilizar o pensamento do outro, o dizer do outro e a possibilidade de, nesse mesmo processo, entretecer os dizeres em circulação, questioná-los, redimensioná-los e sistematizá-los (FonTANA, 2000, p.71).

De forma a dialogar com os problemas práticos e conceituais de aula e, ao mesmo tempo servindo de material da pesquisa, foram utilizados nas aulas conteúdos pedagógicos como os esportes coletivos considerados tradicionais (futsal, voleibol, basquetebol e handebol), que são, muitas vezes, repudiados nos cursos de formação profissional em Educação Física. Isso, porque se criou um estigma adquirido através de oferta de práticas pedagógicas esportivas acríticas.

Tais conteúdos foram escolhidos no sentido primeiro, de evidenciar que a fuga inconsciente destas manifestações por parte dos professores de Educação Física pode acarretar na continuidade da reprodução dos fatores acríticos que interferem a observância destas práticas sociais. Segundo, eles podem apontar para uma condição de intervenção docente que transcende a perspectiva crítico-reprodutivista de ensino. Terceiro, porque as manifestaçōes esportivas fazem parte da realidade social dos alunos apresentando um universo conceitual a ser desenvolvido.

Para eleição dos conteúdos bimestrais contamos com o processo interativo dos alunos na escolha de uma modalidade como tema de aula, e a partir dela foram deflagrados subtemas correlatos. Com a proximidade do megaevento esportivo Copa do Mundo na Alemanha em 2006, a modalidade escolhida pelos alunos foi o futebol. Essa opção também justifica-se porque, como nos lembra DAMatTa (1982), o futebol é aquilo que fazemos dele, assim podemos dizer que com o futebol o homem brasileiro expressa fortes marcas de sua cultura e de seu entendimento do mundo no qual está inserido. 
A partir da escolha do tema o professor/pesquisador encaminhou diferentes subtemas para que fossem desenvolvidos, a saber: a) futebol e grandes empresas; b) futebol e mídia; c) futebol e sociedade; d) futebol e violência; e) futebol e economia; f) futebol e cultura brasileira. Nos bimestres subsequentes o handebol, voleibol e basquetebol foram propostos como conteúdos, não pela prática "per se", mas a partir das experiências e saberes incorporados no bimestre anterior.

Os subtemas foram estudados em sala de aula e na quadra poliesportiva existente na Escola. Para mediação, contou-se com o recurso da Internet, revistas, jornais, comerciais de TV, filmes, relatos de experiência dos alunos, vivência de jogos na quadra e dramatização. Para seleção dos recursos didáticos tomou-se como referência fatores do esporte de rendimento: as formas de vitória a qualquer preço e o esporte como manifestação de consumo com estratégias paradoxais que "fintam" e acentuam os problemas do homem em suas relações sociais.

Para que os resultados das aulas pudessem ser sistematizados e mensurados foi solicitado que os alunos realizassem ao final de cada aula, em casa ou em ambiente escolar, relatórios de cada dia das atividades. A opção pela realização do relatório em um lugar extraaula foi para estimular maior autonomia do estudante na organização de seu pensamento sobre a proposta desenvolvida a ser externada em forma de linguagem.

Para os registros as questôes norteadoras foram: a) qual conteúdo proposto no dia?; b) quais os procedimentos dos jogos e das atividades em sala?; c) o que pensaram durante a realização da proposta?; d) e, o que aprenderam? Os relatórios constituíram-se no elemento primordial que identificou a forma como os alunos reconhecem a prática esportiva futebol e seus fenômenos correlatos.

Apresentaremos neste texto fragmentos dos relatórios confeccionados nos primeiros dois meses e meio de aula. Os relatórios foram produzidos pelos estudantes das séries e da Escola já apresentadas, totalizando 315 alunos na média de idade de 13 anos. Para análise sistematizou-se 10 relatórios, não tendo as questôes de gênero como foco de discussão.

Os relatórios selecionados para análise justificam-se em razão de expressarem a representação de um grupo de indivíduos a respeito do conceito de esporte moderno mediado durante as aulas. Este referencial de seleção aproxima-se do conceito de representações sociais inaugurado por Serge Moscovici. As representações sociais podem ser compreendidas como um conjunto organizado de informaçôes, atitudes, crenças que um indivíduo ou um grupo elabora a propósito de um objeto, de uma situação, de um conceito, de outros indivíduos ou grupos apresentando-se, portanto, como uma visão subjetiva e social da realidade (MoscovicI, 2007).

As aulas ministradas foram permeadas em todos os momentos com experiências que estivessem próximas à realidade dos alunos, neste sentido, os recursos didático-pedagógicos foram constantemente utilizados pelo professor/pesquisador para que os alunos identificassem o esporte moderno enquanto fenômeno social institucionalizado formado por uma rede complexa de interaçóes sociais.

Pautando-se também o fenômeno esporte a partir dos aspectos da teoria dos campos de Pierre Bourdieu (1983, 1990, 2000, 2005) e Bourdieu, Chamboredon e Passeron (2004), estabeleceu-se com os alunos em aula a existência de um campo esportivo que englobasse agentes sociais e ocupantes de postos específicos, que constantemente buscam um lugar social através de disputas, capitais econômicos, políticos e simbólicos. Com auxilio do referencial de Bourdieu, a análise do esporte tornou-se mais complexa e sistematizada nas intervenções e nas investigações efetuadas em conjunto com os alunos.

O projeto seguiu as orientações éticas em pesquisa com seres humanos. Ele foi apresentado e aceito pela Direção da Escola colaboradora, os pais dos alunos assinaram o Termo de Consentimento Informado elaborado conforme Resolução 196/96 do Conselho Nacional de Saúde.

\section{Esporte moderno}

Descrever a importância do esporte na sociedade moderna exemplificando diversos fatos que possam comprová-lo pode ser um tanto perigoso, pois o risco imediato é a explicação por especulações ou por pré-noções. Isso decorre devido à constante presença esportiva que permeia a fala do ser social acometido pelas diversas formas de transmissões esportivas por parte dos meios de comunicação de massa (PIMENTA, 2007, p.23).

Um modelo explicativo é compreender o esporte como um fato social. De acordo com Émile DURKHEIM (1968), constitui-se fato social: 
[...] toda maneira de agir fixa ou não, suscetível de exercer sobre o indivíduo uma coerção exterior; ou então ainda, que é geral na extensão de uma sociedade dada, apresentando uma existência própria, independente das manifestações individuais que possa ter (Durkheim, 1968, p. 12).

Para uma análise mais crítica, reconhece-se que o esporte também faz parte de uma indústria responsável por uma constante de reproduções de instructos e normas. Portanto, estamos diante de um acontecimento que se impóe desde cedo no dia-adia dos indivíduos, assim como o tipo de comida, vestuário, língua ou religião. É um fato social capaz de influenciar os costumes e hábitos das pessoas.

Por estar o esporte constantemente presente na vida ordinária, é que uma análise indicativa dos determinantes históricos e sociológicos do esporte torna-se difícil. Pois os caminhos a serem adotados pelo pesquisador podem possuir os percalços das análises ideológicas que funcionam como limitadoras da realidade.

Para se evitar percalços, reconhece que o esporte é um fato social - a esta altura a sociologia durkheiminiana fornece elementos pertinentes - porque é detentor de uma organização definida e tomada como prática coletiva repleta de crenças e tendências. Essa afirmação auxilia referenciais teóricos que tratam o esporte como fato social dotado de valores sociais, econômicos, políticos e históricos, responsável por uma "força coerciva exterior".

Em uma outra perspectiva, a de Pierre BourDIEU (1983), em “Como é possível ser esportivo?”, encontra-se a concepção de que o esporte moderno é um fenômeno que ocupa um lugar de práticas sociais denominado de campo. O campo esportivo é constituído por uma história e lógica próprias, no seu interior há instituições, agentes (praticantes, espectadores, dirigentes, professores, jornalistas, comerciantes, entre outros), práticas e distinções sociais movidos por competências específicas tão significativas como o capital social, cultural ou econômico. O campo das práticas esportivas é o lugar de lutas que, entre outras coisas, disputam o monopólio de imposição de definição legítima da prática esportiva e da função legítima da atividade esportiva, amadorismo contra profissionalismo, esporte-prática contra esporte-espetáculo, esporte distintivo - de elite - esporte popular - de massa - etc.; e este campo está ele também inserido no campo das lutas pela definiçāo do corpo legítimo e do uso legítimo do corpo, lutas que além de oporem entre si, treinadores, dirigentes, professores de ginástica e outros comerciantes de bens e serviços esportivos, opõem também os moralistas e particularmente o clero, os médicos e particularmente os higienistas, os educadores no sentido mais amplo [...] (Bourdieu, 1983, p.142).

No campo esportivo os agentes a partir de seus conhecimentos entram em constantes disputas ligadas aos interesses específicos e ao poder simbólico. O movimento das concorrências diz respeito às relações sociais estabelecidas na prática cultural e no consumo, na oferta e na demanda do esporte - semelhantemente as normas orientadoras do mercado de produtos e consumidores. Para Bourdieu o esporte moderno tem natureza sociocultural articulada com a sociedade marcada pelas relaçôes socioeconômicas. É por isso que para o autor é possível visualizar a formação do campo esportivo quando:

Parece indiscutível que a passagem do jogo ao esporte propriamente dito tenha se realizado nas grandes escolas reservadas à 'elites' da sociedade burguesa, nas public schools inglesas, onde os filhos das famílias da aristocracia ou da grande burguesia retomaram alguns jogos populares, isto é, vulgares, impondo-lhes uma mudança de significado e de função muito parecida àquela que o campo da música erudita impôs às danças populares [...] Para caracterizar os princípios desta transformação, pode-se dizer que os exercícios corporais da "elite" foram separados das ocasiōes sociais ordinárias às quais os jogos populares permaneciam associados (festas agrárias, por exemplo) e desprovidos das funçōes sociais (e, a fortiori, religiosas) ainda ligadas a vários jogos tradicionais (como os jogos rituais praticados em muitas sociedades pré-capitalistas em certas passagens do ano agrícola). A escola, lugar da skhole, do lazer, é o lugar onde as práticas dotadas de funções sociais e integradas no calendário coletivo, são convertidas em exercícios corporais, atividades que constituem fins em si mesmas, espécie de arte pela arte corporal, submetidas à regras específicas, cada vez mais irredutíveis a qualquer necessidade funcional, e inseridas num calendário específico. (Boudieu, 1983, p.139; Itálico do autor).

Portanto, o esporte moderno na concepção de Bourdieu tem sua gênese nos jogos populares, produzidos pelo povo, que após suas transformaçóes pela burguesia ascendente retorna ao povo, como "folk music", sob a forma de espetáculos produzidos para o povo. Este processo acompanha a racionalização desenvolvida pelo Estado num sentido weberiano, a dimensão de uma filosofia política, os lucros de distinção e os espetáculos produzidos por profissionais vendidos em "show business" como mercadoria de consumo de massa. 
Assim, o caráter mítico das antigas manifestações corporais de competição que buscavam a aproximação com suas divindades extras corpóreas, irrompeu-se para o jogo/esporte secular fundando estruturalmente no valor da prática esportiva propedêutica. Neste sentido, os agentes que, de formas específicas, perfilham o campo esportivo contemporâneo, reconheceram sua prática em termos de trabalho racionalizado, ou seja, tomando-o como manifestação séria.

É pertinente recordar o discurso de atletas, que ao saírem de seu trabalho (no campo, na quadra, na pista), inauguram a participação nos comentários da mídia esportiva manifestando de forma transparente a imbricada relação entre esporte e trabalho: "Nós estamos fazendo nossa parte, trazendo alegria para esse povo que sofre tanto...”. Isto é, os atletas trabalham para potencializar momentos lúdicos esportivos. Desse modo no campo esportivo o ser atleta profissional torna mais sério, atrativo, gratificante e ainda pode garantir um futuro social diferente.

Esse discurso, acompanhado da portentosa campanha de propagandas midiáticas, estabelece uma comunicação que objetiva:

[...] instituir no imaginário coletivo uma representação sobre o esporte como sendo uma das práticas sociais mais eficazes que o poder público, em conjunto com a sociedade, incentivaria, para que assim atingisse objetivos tais como: "retirar as crianças da rua"; "afastar os jovens e adolescentes das drogas"; "incentivar a prática de uma educação social solidária"; "melhorar o comportamento social e escolar das crianças e

\section{Esporte na escola}

Historicamente, a Educação Física escolar tornou-se perigosamente sinônimo de esporte. As diferentes manifestaçôes culturais ficaram à mercê da marginalidade dos conteúdos apreendidos pelos alunos. Outras manifestaçōes corporais, que também não deixam de ser esportivas, como a ginástica, o atletismo, as lutas e as modalidades de pranchas, foram sendo renegadas à medida que as quatro modalidades - futsal, handebol, voleibol e basquetebol - tornaram-se parte integrante da pedagogia nas aulas de Educação Física.

[...] mesmo passando por inúmeras transformaçōes nas últimas décadas, especialmente a partir de 1980, a Educação Física brasileira ainda traz como consenso que seu conteúdo é o esporte adolescentes"; "desenvolver o espírito cívico e esportivo"; "incentivar a prática do esporte para a melhoria da saúde e qualidade de vida da população"; e "possibilitar a ascensão socioeconômica dos jovens das camadas populares" (PIRES, Calciolari Junior \& Honorato, 2008, p.10).

Essas representações sociais, diversas vezes emergem nos discursos proferidos por atletas de diferentes modalidades e por agentes do poder público. Elas elucidam a forma como o esporte é tratado e compreendido por parte dos formadores de opinião e dos espectadores.

$\mathrm{Na}$ sociedade moderna é prática comum reduzir o esporte a uma manifestação de ordem psicológica que exerce influência nos ânimos populares. É fácil optar por determinada explicação uma vez que estabelece um patamar limitado, situando-o como um fenômeno imutável.

É possível formar um quadro elucidativo do esporte e sua transposição mimética para a área social, educacional e empresarial, uma vez que se admite tomá-lo como manifestação em crescente expansão, tanto em termos evidentemente geográficos, quanto em termos acadêmicos científicos que almejam sua compreensão e sua relação social. Sem considerar, o bordão "melhoria da qualidade de vida" que vem arraigado ao esporte de alto rendimento na medida em que ele se tornou, equivocadamente, uma manifestação de boa saúde valorizada pelas vitórias atléticas excepcionais. A questão é que na sociedade moderna o esporte é um fenômeno de senso comum, por isso ele não é menor, e sim fundamental para o viver em sociedade.

federado com suas regras, técnicas e táticas [...]

(BRAsil, 2004, p.52).

Compreende-se que o esporte na escola é supervalorizado pelos professores, que em muitos casos não enxergam que o seu ensino, enquanto manifestação imutável ou permeado por modismos apenas, é limitador dos caminhos necessários para trilhar no intuito de se conseguir o objetivo da Educação Física escolar proposto, à guisa de exemplo, por BETTI e ZuLLIANI (2002, p.75):

[...] introduzir e integrar o aluno na cultura corporal de movimento, formando o cidadão que vai produzi-la e transformá-la, instrumentalizando-o para usufruir do jogo, do esporte, das atividades rítmicas e dança, das ginásticas 
e práticas de aptidão física, em benefício da qualidade da vida.

O esporte na escola muitas vezes é consequência do ensino fracionado, analítico e diretivo da técnica esportiva. Esta forma de ensino, herança de um pensamento funcionalista, vê no aluno um indivíduo formado por um conglomerado de células. A perspectiva do ser social é posta de lado. O reconhecimento do aluno como atuante na sociedade, em constante processo de socialização é pouco evidenciada (DuBAR, 2005). Mas designar o problema apenas ao professor seria limitar a análise marginalizando a complexidade histórica que constitui a instituição escolar.

Não apenas o professor de Educação Física aquilata o esporte como ferramenta única em seu magistério, mas todo o conjunto inter-relacionado e interdependente, ou seja, os agentes escolares distinguem a prática profissional em Educação Física como uma constante esportiva, neste sentido, estranhando qualquer utilização de recurso aquém das manifestações do esporte voltado ao desempenho físico-motor.

Entre os agentes escolares encontram-se, por exemplo, diretores, vice-diretores e coordenadores pedagógicos que, em muitas instituiçôes de ensino, indagam ao professor o significado do esporte e, não satisfeitos, realizam a famosa pergunta: "não tem campeonato neste bimestre?".

Culpar seria eximir a realidade histórico-cultural de suas perversōes apriorísticas, além de constituir-se em juízos de valor, uma vez que os círculos sociais, querendo ou não, são frequentemente bombardeados pelos discursos esportivos referenciados na mídia. Destaca BETTI (2002), seja na condição de praticante ou espectador se produz a falação esportiva após experimentar elementos da cultura esportiva: "você

\section{Resultados}

O professor/pesquisador ao assumir o papel de mediador intencional buscou explicitar a elaboração conceitual dos estudantes frente ao conteúdo esporte moderno. O conceito de esporte passou a ser apresentado, problematizado e sistematizado à luz de informações e sentidos da experiência escolar e não-escolar dos estudantes. A mediação pedagógica ocorreu a partir de vivências de jogos de futebol (Alberti \& Rothenberg, 1984; Freire, 2003; SanTANA, 2004) e de processos de busca sobre o tema e seus fenômenos correlatos: grandes empresas, mídia, sociedade, violência, economia e cultura brasileira. viu aquele jogo?", “aquele cara não joga nada!". Falar de esporte é legal, é bonito, é sinal de "status" e uma forma de reforçar laços sociais.

Portanto, a escola não fica aquém dos discursos televisivos midiáticos, uma vez que ela se torna local de reproduções imagéticas fundamentalmente veiculadas pela TV, contudo nós professores precisamos buscar caminhos para irmos além de uma visão crítico-reprodutivista. Reverenciar a prática esportiva de rendimento como contexto único nas aulas de Educação Física é cometer um "suicídio pedagógico", é uma limitação sobre a cultura esportiva por parte do professor. Isso não significa que o docente deva romper seus "laços esportivos" e dizer: "eu nunca mais vou ensinar esporte". Talvez nesta afirmação encontra-se o engano: o que seria ensinar esporte afinal? A resposta virá a romper com a visão funcionalista de causa e efeito, caso a análise do esporte pelo senso comum seja considerada e problematizada almejando novas sistematizaçóes.

Na formação de professores de Educação Física no ensino superior, muito se ouve sobre o esporte como veículo de consumo, como ferramenta de "inculcação" de ideais dominantes, mas pouco se fala sobre o conhecimento de esporte que o aluno traz consigo para o professor nas aulas de Educação Física escolar. Então indagamos: como o aluno interpreta o esporte e acima de tudo, como ele vêo ensino do esporte nas aulas de Educação Física? Como se dá a construção do "habitus" deste aluno e sua influência, no que concerne à sua visão esportiva? Avançando, como ele apreende sua concepção de esporte?

Tendo como premissa que os alunos possuem um conhecimento embasado pelo senso comum, foi que iniciamos um estudo que objetivasse instigar a abstração por parte dos alunos, sobre o conceito de esporte e os seus fenômenos correlatos.

Como resultado inicial, observou-se que $100 \%$ das pesquisas realizadas pelos alunos para confecção dos relatórios limitaram-se pela reprodução de fontes de informação adquiridas pela Internet. Essa ação reforça o sentimento sobre a importância da rede mundial de computadores na vida das gerações contemporâneas. Para ampliar as fontes de conhecimento e informação o mediador pedagógico propôs a procura de novos recursos presentes em suas vidas para que desenvolvessem também a capacidade de criação e de leituras diferentes, a partir de outro ângulo social. As fontes apresentadas ao professor/pesquisador foram então: 
fragmentos de jornais/revistas/Internet, comercial de TV, filmes e relatos de experiência.

A perspectiva de intervenção pedagógica tornou-se mais complexa, uma vez que o conceito de esporte tornava-se polissêmico. Assim, no desenvolver das aulas teórico-práticas o professor foi aos poucos dialogando sobre conceitos como competitividade, exclusão, cultura, política, sociedade e economia. A introdução desses conceitos, associada ao auxílio de saberes adquiridos em outros componentes curriculares foi fundamental para uma ação interdisciplinar no ato da realização das conceituações, problematizações e sistematizaçōes que apresentaremos a seguir referendando fragmentos dos relatórios elaborados pelos estudantes.

\section{Discussão}

\section{Futebol e grandes empresas}

Nós aprendemos que as grandes empresas podem estar no futebol, como por exemplo, a Petrobrás que agora na Copa paga as passagens dos jogadores, a Nike que dá os uniformes e as chuteiras. Outras como a Adidas, a Coca-Cola, McDonald's e muitas outras patrocinam de outro jeito. (Relatório: Aluno - $6^{a}$ Série).

Os alunos iniciaram a produção de conhecimento sobre os patrocínios e, a partir de exemplos expostos na mídia nomearam grandes marcas presentes na Copa do Mundo de Futebol realizada na Alemanha em 2006. Essa interpretação aponta para a força da mídia, do marketing e da organização esportiva.

Conforme Proni (1998), a história recente do futebol tem sido marcada pela importância crescente do marketing no financiamento das competições e pela sua transformação em empresa e esporte-espetáculo formando uma cultura de consumo, potencializando a mercantilização do mundo esportivo.

A problematização desenvolvida em conjunto com os alunos foi de que as empresas e os meios de comunicação exercem uma força simbólica. A força simbólica remete ao espectador profundas ondas de marasmo, nas quais os indivíduos apenas reconhecem de forma passional os patrocinadores e não se preocupam na análise objetiva dos fatos que levam empresas privadas/públicas ao investimento expressivo nas modalidades esportivas de rendimento.

O esporte moderno como fenômeno - dotado de valores sociais, econômicos, políticos e históricos - responsável por forças coercivas exteriores, pode incitar o exercício da apreciação substancialista no senso comum por parte do homem em seu cotidiano.

A análise das práticas esportivas como pertencentes a um campo remete à ideia de um espaço social repleto de seres sociais que, por definição de seus habitus (BOURDIEU, 2000), são agenciadores de formas específicas de lucros e concorrentes entre si por oportunidades de apropriação de mais capitais sejam eles econômicos, sociais, culturais ou simbólicos. Segundo Bourdieu, Chamboredon e PasseRON (2004, p.65) a "dificuldade que é particular à aplicação deste modo de pensamento às coisas do mundo social, provém da ruptura com a percepção comum do mundo social por este exigida”.

O Brasil investe em muita coisa, por exemplo, pratos, chinelos, camisetas, carteiras, chuteiras, blusas, shorts, cornetas, apitos. Tudo isso para a grande torcida rumo ao hexa [...] Muitas pessoas não perdem a esperança e as grandes empresas não param de crescer. Fazendo coisas para nos deixar felizes e contentes nesta Copa [...] Todas as vezes que tem Copa as grandes empresas sempre saem ganhando. Sem contar quanto os jogadores ganham! [...] E o que acontece com aquelas pessoas que moram na favela? [...]. É por isso que acho que devemos saber o que fazer com essas pessoas que não tiveram essa oportunidade de ser jogador; e também acho que é pela cor da pele. Isso é racismo. (Relatório: Aluno - $\sigma^{a}$ Série).

Conceitos como exclusão social e preconceito podem ser vistos nesta interpretação. Pela palavra racismo, percebe-se uma das formas de exclusão evidenciadas no esporte e os alunos expuseram em suas reflexões em aula.

A consciência de um campo esportivo, associada à ideia de teias de interdependência de ELIAS (1992), traz a noção de movimento aos campos. Neste sentido têm-se os agenciadores de capitais que, além de encontrarem-se constantemente em conflitos por apropriações, permanecem na dependência das atitudes de outros agentes, pois dada a complexidade da estrutura de seus campos, cada movimento em seu interior acarreta uma consequência negativa ou positiva, a partir do ponto de vista social em que se encontra determinado agente. 


\section{Futebol e mídia}

Alguns dos trabalhos elegeram exemplos de como a atuação da mídia é presente no futebol e provoca sentimentos inconfortáveis. Para tanto, os alunos fizeram uso da reprodução de reportagens de jornais e Internet:

Mídia brasileira bate recordes na Alemanha; mídia alemã fica pequena com a "invasão" brasileira na copa; altos investimentos em coberturas especiais e a aposta no hexacampeonato mundial por parte da seleção brasileira levam a mídia verde-amarela à recorde de pessoas trabalhando no Mundial; grupos de comunicaçôes montaram até estúdios. (Relatório: Aluno - 6a Série, fragmento de jornal).

A problematização realizada com os estudantes foi questionar qual o lugar social do espectador na transmissão dos megaeventos esportivos. A sistematização desencadeada foi que os veículos midiáticos desejam instituir formas de comportamentos, de poder e de interesses mercantis movidos por agenciadores de capitais tornando o esporte cada vez mais complexo.

Pela mídia o campo esportivo com uma estrutura simbólica exerce a imposição e propagação de valores. Para BETTI (2004), a televisão torna os espectadores "autoridades" em temas esportivos e os esportes em espetáculos, particularmente quando o televisionamento enfatiza mais o espectro de cobertura que o próprio acontecimento da partida.

Durante as aulas foi possível observar sentimentos de revolta em relação à espetacularização do futebol: Atividade da aula: foi sobre o esporte-espetáculo; Procedimentos: quando passa um comercial e está passando jogo, eles cobram uma taxa muito cara;

O que senti: eu senti raiva, porque é pelo nosso bolso que esses 'caras' ficam ricos;

O que aprendi: eu aprendi, a nunca mais assistir jogos e comerciais. (Relatório: Aluno - $7^{\mathrm{a}}$ Série).

O desafio da mediação pedagógica proposto ao profissional de Educação Física frente aos veículos midiáticos não é o de criar repugnância total ao esporte moderno espetacularizado, e sim usar a seu favor o arcabouço de informação esportiva que circula nos meios de comunicação. É importante por meio das imagens esportivas atrair e sensibilizar o outro para reflexão e ação, minimizando o estado de passividade do sujeito. Para tanto, considerar o universo imagético dos alunos faz-se necessário para elucidar ideologias presentes nas imagens dos meios de comunicação e mediar produçõoes de diferentes conceitos e práticas sobre o esporte moderno.

\section{Futebol e sociedade}

Claro que tal violência não tem origem apenas na rivalidade futebolística, mas também em outros fatores, como os problemas sociais, étnicos e até religiosos. Não é uma pessoa sequer que, quando pratica o futebol com os amigos, ou na escola, ou no campo do bairro que muda as regras do jogo e faz as próprias regras. Quantas vezes jogamos sem ninguém apitando o jogo?! (Relatório: aluno - $\sigma^{a}$ Série, fragmento de Internet).

Com os alunos foi problematizada a relação entre indivíduo e sociedade a partir do universo futebolístico. A primeira sistematização foi que indivíduo, esporte e sociedade não são três estruturas estanques, e sim interdependentes socialmente (ELIAS \& DUNNING, 1992). O esporte moderno colabora com a compreensão do desenvolvimento do indivíduo e da sociedade, e estes dois com a compreensão do esporte como atividade social.

A segunda sistematização desenvolvida foi que as regras esportivas são produções de necessidades sociais específicas e podem ser criadas, modificadas, ou até mesmo anuladas, a partir dos indivíduos e do lugar social. Logo, as regras esportivas não devem ser exteriores aos indivíduos que vivem, segundo GARRIGOU (2001), em um grande jogo social. Então, as regras foram consideradas como representações sobre as necessidades de um grupo de agentes específicos. Com este entendimento destacaram-se três particularidades das regras: adaptação, agentes específicos e interesses sociais.

Os alunos sistematizaram também, com dificuldades de distinção objetiva, que o esporte na vida social tem suas variações: de prática de rendimento a manifestaçõos de lazer. Nas dramatizações organizadas e realizadas pelos alunos em aula, a representação do esporte como manifestação lúdica era permeada pelas imagens hegemônicas e modelares dos três "R's": "Ronaldinhos", "Ronaldos" e "Robinhos". Os três "R's” eram sinônimos de vitória na vida social e econômica a partir do futebol mercantilizado e espetacularizado. Então, o desafio pedagógico foi mediar que há um poder simbólico exercido através do esporte que se torna ferramenta de inculcação dos ideais hegemônicos do subcampo esportivo futebol.

Para problematizar o inconformismo lógico dos alunos, o referencial de Pierre Bourdieu foi pertinente. Pois para o autor a força do poder simbólico a ser descoberta está onde a coerção se deixa ver menos, onde ela é mais ignorada, portanto, reconhecida. "O poder simbólico é, com efeito, esse poder invisível o qual só pode ser exercido com a cumplicidade daqueles que 
não querem saber que lhe estão sujeitos ou mesmo que o exercem" (BouRdiEU, 2000, p.7-8). É esse poder simbólico exercido que faz com que os seres sociais, não dotados de capital cultural necessário, absorvam facilmente as manifestações hegemônicas inculcadas por meio do exercício de violência simbólica.

O poder simbólico como o carisma transmitido pelo atleta, advém das manifestações do poder simbólico exercido e mantido pelos agentes no topo da hierarquia burocrática do campo esportivo. Este poder carismático, para BONNEWITZ (2003) é a forma de poder:

[...] conferido aos indivíduos supostamente dotados de qualidades especiais que lhes asseguram uma irradiação social excepcional, está baseado numa delegação de poder dos dominados em benefício do dominante, que só faz exercer sobre aqueles o poder que eles próprios depositaram em suas mãos (p.103-4).

Assim, os espectadores que veem o agente esportivo como detentor de valores supremos, como ídolos e como modelos a serem seguidos, podem deixar a compreensão da realidade social mais turva do que já é por essência.

\section{Futebol e violência}

A questão mediada com os alunos foi: quais os tipos de violência presentes no subcampo esportivo futebol? A violência nos deixa com medo em certas ocasiōes, com medo até de sair nas ruas. No caso do futebol com suas torcidas organizadas, não temos nem coragem de ir a um estádio torcer ou ver uma partida de futebol. (Relatório: Aluno - $6^{a}$ Série).

Entendemos que a violência está dentro e fora do campo. Ela é praticada por jogadores e torcedores. Existem vários tipos de violências que aparecem neste esporte: a violência física, verbal e moral. (Relatório: Aluno - $7^{a}$ Série).

Nestes relatos os alunos se posicionaram diante da violência no futebol e sua relação quanto à diminuição de espectadores nas partidas futebolísticas. Os tipos de violência sistematizados em aula foram: violência entre torcedores, violência entre os jogadores, violência física e violência simbólica. Essa tipificação nos aproxima dos estudos de Elias e DunNing (1992) e Reis (2005). Assim pôde se considerar com os alunos que os tipos de violência são produzidos pelos seres humanos de formas diversas e complexas. Os confrontos violentos relacionados ao espetáculo futebol ocorrem quando há um desequilíbrio de forças entre os envolvidos e um grupo (ou mais grupos) sente-se no direito de fazer uso da força física (agressão corporal) ou simbólica (expressōes verbais de "baixo calão").

Para os alunos a violência no futebol não se resume aos eventos de multidão, ela se faz presente em acontecimentos de seu cotidiano escolar:

$\mathrm{O}$ quê? A escola tem com isso. A violência no futebol não se limita aos torcedores: envolve jogadores, alunos contra alunos e professores contra professores. Nos jogos entre escolares as observações têm demonstrado que as menores ocorrências de agressão e violência são os casos envolvendo aluno-atleta contra aluno-atleta devido ao respeito entre iguais e quando perdura após os eventos revela outras origens como gangues. (Relatório: Aluno - $7^{a}$ Série, fragmento de Internet).

Nas reflexões dos alunos foi possível observar que o esporte, objetivando rendimento praticado nas turmas de treinamento escolar, vem a apregoar valores necessários à prática esportiva sem violência. Paradoxalmente, mesmo os estudantes repudiando a violência e sabendo que os jogos para multidóes muitas vezes se tornaram palco da violência, acreditam na pacificação das relaçōes sociais pelo esporte e revelam o desejo de ser atleta de futebol para disputar partidas espetacularizadas para conquistarem recursos econômicos.

\section{Futebol e economia}

Nós brasileiros, amantes do futebol, em ano de Copa do Mundo, gastamos muito dinheiro para entrar no clima de festa e torcer pelo Brasil, a nossa pátria amada. Buscamos no futebol uma forma de lazer e descanso. E como é bom quando você pode torcer com uma corneta, uma camisa, um boné e outros produtos. (Relatório: Aluno - $\sigma^{\mathrm{a}}$ Série).

Neste fragmento pode ser evidenciada a noção latente de consumo por parte dos educandos. A relação objetiva e a força atrativa dos produtos vêm expressar-se como componentes no cotidiano dos alunos.

Fica concluído que as pessoas gastam muito dinheiro (em média 1.500 reais) para torcer pelo nosso país em ano de Copa do Mundo. Isso é muito bom, não apenas para entrar no clima do Mundial, também para tornar o futebol um esporte ainda mais grandioso do que já é. (Relatório: Aluno - $\sigma^{a}$ Série).

Os alunos, mesmo conscientes da relação entre o consumo e a economia, ainda não reconhecem a relação negativa de sua excessiva manifestação. No intuito de contribuir aos estudos do esporte é necessário preocupar-se em analisar seus elementos como: espetacularização e o consumo. Como também aponta Ademir Gebara (2000): 
Pois bem, se vamos às áreas de conhecimento que nos permitem teorizar sobre esta matéria (História, Sociologia, Antropologia), e se temos entranhada esta dimensão da atividade física, onde a sua prática é o elemento encaminhador de nosso raciocínio, cometemos um equívoco perigoso. Creio mesmo que a chamada crise da "Educação Física" é fruto deste equívoco. Simplesmente nos esquecemos que, do ponto de vista do esporte, mais nitidamente exemplificado com a NBA; ou mesmo na óptica do lazer, como por exemplo, com os parques temáticos, o aspecto condutor de nosso raciocínio deve ser o consumo, que se verifica claramente a partir da espetacularização destas atividades (p.5).

\section{Futebol e cultura brasileira}

Alguns alunos pesquisaram em fontes eletrônicas a relação entre o futebol e a cultura. Então, problematizamos: qual a relação entre o futebol e a cultura brasileira? Para responder a essa indagação os alunos reproduziram em seus relatórios textos como a entrevista do então Ministro da Cultura Gilberto Gil:

O futebol tem muitas dimensões que se entrelaçam, formando um mosaico amplo, variado e global. Ele pode ser encarado como espetáculo, competição, ritual, metáfora, celebração, síntese, catarse. [...]

\section{Considerações finais}

Os alunos conceituaram, inicialmente, o esporte moderno como uma prática técnica e regrada tipicamente organizada pelas federações. O conceito de esporte era reproduzido como constante universal pelos alunos a partir do que eles ouviam nos meios de comunicação, o que contribui para a idolatria dos agentes sociais (atletas e técnicos) do campo esportivo. O pensamento dos estudantes sobre esporte colocava-os na posição submissa diante do fenômeno esportivo, mantendo o reduzido nível de criticidade e alto potencial de consumo.

Com auxílio da proposta da mediação pedagógica, da pesquisa participante e dos saberes socioculturais do esporte, foi possível durante as aulas de Educação Física problematizar e sistematizar com os alunos que o esporte tem outras dimensões, entre elas: relações mercantis, comunicação de massa, reprodução dos espetáculos em imagens e discursos, violência simbólica como distinção social, cultura popular, regras mutáveis a partir dos praticantes e do lugar social.
Mas não há apenas um futebol [...] cada sociedade tem o seu modo próprio de jogar e de torcer, resultado de sua história e de sua cultura. (Relatório: Aluno - $7^{\text {a }}$ Série, fragmento de Internet).

Os alunos encontraram uma fonte que expressa a cultura e o futebol não apenas como manifestações artísticas, mas como elementos integrantes e presentes no imaginário nacional que inspira atitudes. Então sistematizaram:

Nós entendemos que o futebol e a cultura brasileira estão ligados, porque a própria cultura brasileira é o futebol. A cultura brasileira está relacionada à tudo, uma coisa puxa a outra, porque o futebol é muito conhecido. Conhecendo o futebol, acaba-se conhecendo a cultura brasileira, formando um só. (Relatório: Aluno - $6^{a}$ Série).

Os estudantes perceberam o inter-relacionamento expressivo que possui o futebol e seu contexto cultural. Por maiores que sejam as dificuldades em expressarem este conhecimento, foi possível evidenciar que os alunos reconheceram o futebol enquanto uma manifestação repleta de bens culturais. O futebol como uma das principais manifestações culturais da nossa sociedade exige, conforme DaOlo (2005), análise que concilie razão e emoção, ciência e crença, modernidade e tradição, senso comum e científico, enfim, explicite as formas de expressão da cultura popular brasileira.

Mais do que o esporte conceituado enquanto campo sociocultural dinâmico, dotado de autonomia e de bens simbólicos e objetivos, a mediação pedagógica desenvolvida objetivou produzir com os alunos mudança de pensamento frente ao fenômeno estudado. Pois as características apregoadas pela perspectiva funcionalista de ensino de esporte, precisam ser superadas para o estabelecimento de relaçóes de ensino e esportivas mais ativas e críticas no contexto da escola. Contudo para os alunos reformularem de maneira duradoura seus pensamentos e suas tomadas de decisões referentes ao esporte moderno, torna-se fundamental reestruturar seus "habitus" esportivos.

A reestruturação do habitus esportivo envolverá não só a escola, mas também todo o universo social no qual o aluno está inserido. Assim, os pensamentos e comportamentos esperados devem ser observados ao longo da vida, portanto, indicando que a formação crítica do aluno sobre o fenômeno esporte, deve ser mediada como constante no processo de ensino e 
aprendizagem na escola. Por fim, esta perspectiva de formação humana torna-se plausível com um corpo de educadores engajados na produção e mudança de pensamentos e comportamentos, na medida em que o trabalho pedagógico na clausura dificilmente gerará frutos consistentes.

\begin{abstract}
Sports and pedagogic mediation

This study analyzed the students' knowledge about the phenomenon "modern sport". The objective was to identify, mediate and problemize the concept of sport formed by students. The prospect of mediation teaching, in particular the contributions of FONTANA (2000), and reading sociology of BOURDIEU (1983) were theoretical grounds for thinking the concepts of sport produced in class. The research, characterized as participant, was performed with students of sixth and seventh grades at a state school in the city of Sao Paulo. Data were classified in reports on lessons mediated by the teacher/researcher. From the pedagogical mediation and analysis of reports can be considered how have changed the thinking of students regarding to the phenomenon of sports in the direction of the sociocultural nature.
\end{abstract}

UnITERMS: Physical education; Pedagogy; Content; Sport; Student.

\title{
Nota
}

Pesquisa realizada durante capacitação docente, nível Lato Sensu em Esporte Escolar, ofertada pela Universidade de Brasília (UNB) em parceria com Ministério do Esporte.

\section{Referências}

ALBERTI, H.; ROTHENBERG, I. Ensino de jogos esportivos: dos pequenos jogos aos grandes jogos esportivos. Rio de Janeiro: Ao Livro Técnico, 1984. (Coleção Educação Física, Prática 10).

BAKHTIN, M. Marxismo e filosofia da linguagem: problemas fundamentais do método sociológico na ciência da linguagem. 10. ed. São Paulo: Hucitec, 2002.

BETTI, M. Imagens em ação: uma pesquisa-ação sobre o uso de matérias televisivas em programas de Educação Física do ensino fundamental e médio. Revista Movimento, Porto Alegre, v.12, n.2, p.95-120, 2006.

Violência em campo: dinheiro, mídia e transgressão às regras no futebol espetáculo. Unijuí, 2004. v.2.

Esporte telespetáculo e mídias: implicaçōes para a qualidade de vida. In: MOREIRA, W.W.; SIMÕES, R. (Orgs.).

Esporte como fator de qualidade de vida. Piracicaba: UNIMEP, 2002.

BETTI, M.; ZULLIANI, L. Educação física escolar: uma proposta de diretrizes pedagógicas. Revista Mackenzie de Educação Física e Esporte, São Paulo, v.1, p.73-81, 2002.

. Educação física, esporte e cidadania. Revista Brasileira de Ciências do Esporte, Florianópolis, v.20, n.2-3, p.84-92, 1999.

BONNEWITZ, P. Primeiras liçóes sobre a sociologia de Pierre Bourdieu. Petrópolis: Vozes, 2003.

BOURDIEU, P. Questóes de sociologia. Rio de Janeiro: Marco Zero, 1983.

Coisas ditas. São Paulo: Brasiliense, 1990.

O poder simbólico. Rio de Janeiro: Bertrand Brasil, 2000. v.3.

Razóes práticas: sobre a teoria da ação. Campinas: Papirus, 2005.

BOURDIEU, P.; CHAMBOREDON, J.; PASSERON, J. Ofício de sociólogo. 4. ed. Petrópolis: Vozes, 2004.

BRASIL. Ministério do Esporte. Esporte e sociedade. 2. ed. Brasília: Universidade de Brasília/Centro de Educação à

Distância, 2004. v.1. 
BRANDÃO, C.R. (Org.). Pesquisa participante. São Paulo: Brasiliense, 2001.

DAMATTA, R. Esporte na sociedade: um ensaio sobre o futebol brasileiro. In: DAMATTA, R. (Org.). Universo do futebol: esporte e sociedade brasileira. Rio de Janeiro: Pinakotheke, 1982.

DAOLIO, J. A superstição no futebol brasileiro. In: DAOLIO, J. (Org.). Futebol, cultura e sociedade. Campinas: Autores Associados, 2005.

DUBAR, C. A socialização: construção das identidades sociais e profissionais. São Paulo: Martins Fontes, 2005.

DURKHEIM, E. As regras do método sociológico. São Paulo: Nacional, 1968.

ELIAS, N.; DUNNING, E. A busca da excitação. Lisboa: Difel, 1992.

FREIRE, J.B. Pedagogia do futebol. Campinas: Autores Associados, 2003.

FONTANA, R.A.C. Mediação pedagógica na sala de aula. 3. ed. Campinas: Autores Associados, 2000.

GARRIGOU, A. O “grande jogo" da sociedade. In: GARRIGOU, A.; LACROIX, B. Norbert Elias: a política e a história. São Paulo: Perspectiva, 2001.

GEBARA, A. História do esporte. In: PRONI, M.W.; LUCENA, R.F. (Orgs.). Esporte, história e sociedade. Campinas: Autores associados, 2000.

LIPOVETSKY, G. A felicidade paradoxal: ensaio sobre a sociedade de hiperconsumo. São Paulo: Companhia das Letras, 2007. MOSCOVICI, S. Representaçóes sociais: investigações em psicologia social. Petrópolis: Vozes, 2007.

NEIRA, M.G.; NUNES, M.L.F. Pedagogia da cultura corporal. São Paulo: Phorte, 2006.

PIMENTA, T. A constituição de um sub-campo do esporte: o caso do taekwondo. 2007. 192 f. Dissertação (Mestrado em Sociologia) - Faculdade de Ciências Sociais, Universidade Federal do Paraná, Curitiba, 2007.

PIRES, A.G.M.G.; CALCIOLARI JUNIOR, A.; HONORATO, T. Representaçóes sociais e imaginário no mundo esportivo. Londrina: Lazer \& Sport, 2008.

PRONI, M. Esporte-espetáculo e futebol-empresa. 1998. 262 f. Tese (Doutorado em Educação Física) - Faculdade de Educação Física, Universidade Estadual de Campinas, Campinas, 1998.

REIS, H.H.B. Espetáculo futebolístico e violência: uma complexa relação. In: DAOLIO, J. (Org.) Futebol, cultura e sociedade. Campinas: Autores Associados, 2005.

RESENDE, H.G. Reflexões sobre algumas contradições da educação física no âmbito da escola pública e alguns caminhos didático-pedagógicos na perspectiva da cultura corporal. Revista Movimento, v.1, n.1, p. 20-28, 1994.

ROCHA, B.; WINTERSTEIN, P.J.; AMARAL, S.C.F. Interação social em aulas de educação física. Revista Brasileira de Educação Física e Esporte, São Paulo, v.23, n.3, p.235-45, 2009.

SANTANA, W.C. Futsal: apontamentos pedagógicos na iniciação e na especialização. Campinas: Autores Associados, 2004. SILVA, C.L.; DAOLIO, J. Comunidades virtuais e Educação Física escolar: reflexões junto a estudantes de Educação Física. Revista Motriz, Rio Claro, v.15 n.4 p.842-9, 2009.

TRIVINÕS, A.N.S. Introdução à pesquisa em ciências sociais: a pesquisa qualitativa em educação. São Paulo: Atlas, 1987. VIGOTSKI, L.S. Génesis de las funciones psíquicas superiores. In: . Obras escolhidas: problemas del desarrolo de la psíque. Madri: Visor, 1995. v.3.

\begin{tabular}{|c|c|}
\hline $\begin{array}{r}\text { ENDEREÇO } \\
\text { Thiago Pimenta } \\
\text { R. José Fernandes Maldonado, 970 - Bloco 1 - apto. } 12 \\
\text { 82840-020 - Curitiba - PR - BRASIL } \\
\text { e-mail: fonsecapi@yahoo.com.br }\end{array}$ & $\begin{array}{l}\text { Recebido para publicação: 22/10/2009 } \\
\text { 1a. Revisão: 15/03/2010 } \\
\text { 2a. Revisão: 14/o6/2010 } \\
\text { Aceito: 14/06/2010 }\end{array}$ \\
\hline
\end{tabular}

